sections (Geology; Geomagnetism and Paleomagnetism; Seismology; Tectonophysics; and Volcanology, Geochemistry, and Petrology) decreased by $54 \%$ over the same period. While sustained growth need not be an objective for one of the two national meetings of the Union, a change in the character of the meeting from one of broad participation to one dominated by fewer than half of the sections is cause for concern.

Responsibility for the health and form of the AGU meetings program resides with the Meetings Committee, now chaired by Katherine Cashman of the University of Oregon. The nature and future of the Spring Meeting has been a prominent agenda item each time the Meetings Committee has met over the past 2 years. In an effort to encourage a focus and an identity for the Spring Meeting that are distinct from those of the Fall Meeting, the Meetings Committee recently took several actions.

The first action changed the structure of the National Program Committee. For many years, the program committees for the two national meetings were chaired by a single Meetings Chair-a position Ronald Zwickl of the National Oceanic and Atmospheric Administration filled ably through last yearand many members of the two committees overlapped. In March 1997 the Meetings Committee recommended that the program committees for the Fall and Spring Meetings be separated completely, with distinct committee chairs. As a result, the Spring Meeting this year will be the first organized by a program committee that had not been preoccupied the previous fall with another national meeting. The Spring Meeting Chair for 1998 is Thomas Herring of the Massachussetts Institute of Technology; he will be succeeded for the 3 years to follow by Carol Simpson of Boston University. The new Fall Meeting Chair, as of last month, is Robert Duce of Texas A\&M University.

In its second major action the Meetings Committee experimented with changes in venue. The Spring Meeting will be in Boston this year and in Baltimore again in 1999. While sites for succeeding years are not yet set, a return to Boston in 2000 and a meeting in Quebec in 2001 are under discussion. The Boston setting has stimulated considerable section interest, an important measure of which is the number of special sessions being organized. The AGU web page currently lists 10 Union sessions and 107 special sessions organized by one or more sections, a total nearly $40 \%$ greater than at the 1997 meeting. Thirty two of those special sessions have been organized by the solid Earth sections. Algorithms used by meeting planners to estimate meeting size indicate that the 1998 Spring Meeting could be the largest ever held.
Even so, the Spring Meeting will have a more relaxed feel than the Fall Meeting, and there is room for new activities. The Meetings Committee has elected to highlight education and public affairs at Spring Meetings in addition to the traditional research topics This year, four Union sessions have a primarily educational focus, as do several sessions organized by the sections. Session themes with strong public policy aspects range from the human dimension in Earth system models to seismic source characterization under the Comprehensive Test Ban Treaty to Boston Harbor as an example of an urban estuary. To encourage AGU members to present papers on public policy and education topics, last May AGU Council approved a request from the Meetings Committee to raise the limit of one contributed paper per first author for the Spring Meeting, and all but one section have waived the limit. To increase student atendance, AGU has arranged for discounted housing in nearby dormitories, reduced the registration fee for undergraduates, and is providing grants for student vanand car-pools.

With all of these changes, the character and content of the Spring Meeting this year will be unlike any that have gone before. I hope that many of you will join me this May for a week in "the hub of the solar system." -Sean C. Solomon, AGU President

\title{
New Constraints on Plate Tectonic Puzzle of the SW Pacific
}

S. C. Cande, J. Stock, C. Raymond, and R. D. Müller

\section{PAGES $81-82$}

A long-standing problem in the tectonics of the southwest Pacific has been the lack of closure of the plate circuit linking the Antarctic, Australia, Lord Howe Rise, and Pacific plates in late Cretaceous and early Tertiary time [Molnar et al., 1975]. Avoiding unacceptable overlaps and underlaps in reconstructions of these plates requires invoking relative motion on one or more nebulous plate boundaries somewhere along the plate circuit, such as between East and West Antarctica, within West Antarctica [Stock and Molnar, 1987], or perhaps between the Lord Howe Rise and Challenger Plateau in the Tasman Sea [Lawver and Gahagan, 1994]. This

For more information, contact S. C. Cande, Scripps Institution of Oceanography, La Jolla, CA 92093-0215, USA. problem is of more than mere local interest since the motion of the Pacific plate relative to the rest of the globe is constrained through its connection with West Antarctica.

The primary barrier to improving southwest Pacific plate reconstructions has been the lack of marine geophysical observations across several key tectonic boundaries. In the past two austral summers, three cruises have collected magnetics, gravity, swath bathymetry, and seismic reflection data in critical areas of the south Tasman Sea and the Southern Ocean off Antarctica (Figure 1). These cruises, R/V Ewing leg 95-13 (purple track), R/VIB Palmer leg 96-02 (dark green) and Palmer leg 97-02 (red), involved scientists and students from Scripps Institution of Oceanography, California Institute of Technology, and the University of Sydney.

These cruises focused on three main areas of interest. One was a spreading corridor of the Southeast Indian Ridge (SEIR) east of the Balleny fracture zone (dark green region in Figure 1). Early Tertiary spreading rates in this corridor were faster than along the rest of the SEIR [Stock and Molnar, 1982]. Because the southeast end of this corridor abuts the region north of the Iselin Bank, spreading within it may reflect motion between Australia and West Antarctica. Consequently, mapping magnetic anomalies along this corridor may enable direct calculation of motion between East and West Antarctica.

A second area of interest was two basins straddling the Macquarie Ridge complex (pink region in Figure 1). These poorly surveyed basins (the Emerald Basin to the south and a region called Southeast Tasman Oceanic Crust [Wood et al., 1996] to the north) are the only locations where magnetic anomalies and fracture zones created by relative motion between the Pacific and Australian plates can be identified.

The third area of interest contains late Cretaceous and early Tertiary magnetic anomalies and fracture zones generated by Pacific-Antarctic spreading off Marie Byrd Land and Thurston Island, West Antarctica. Stock and Molnar [1987] had speculated that there had been relative motion within the Antarctic plate across a boundary near the 


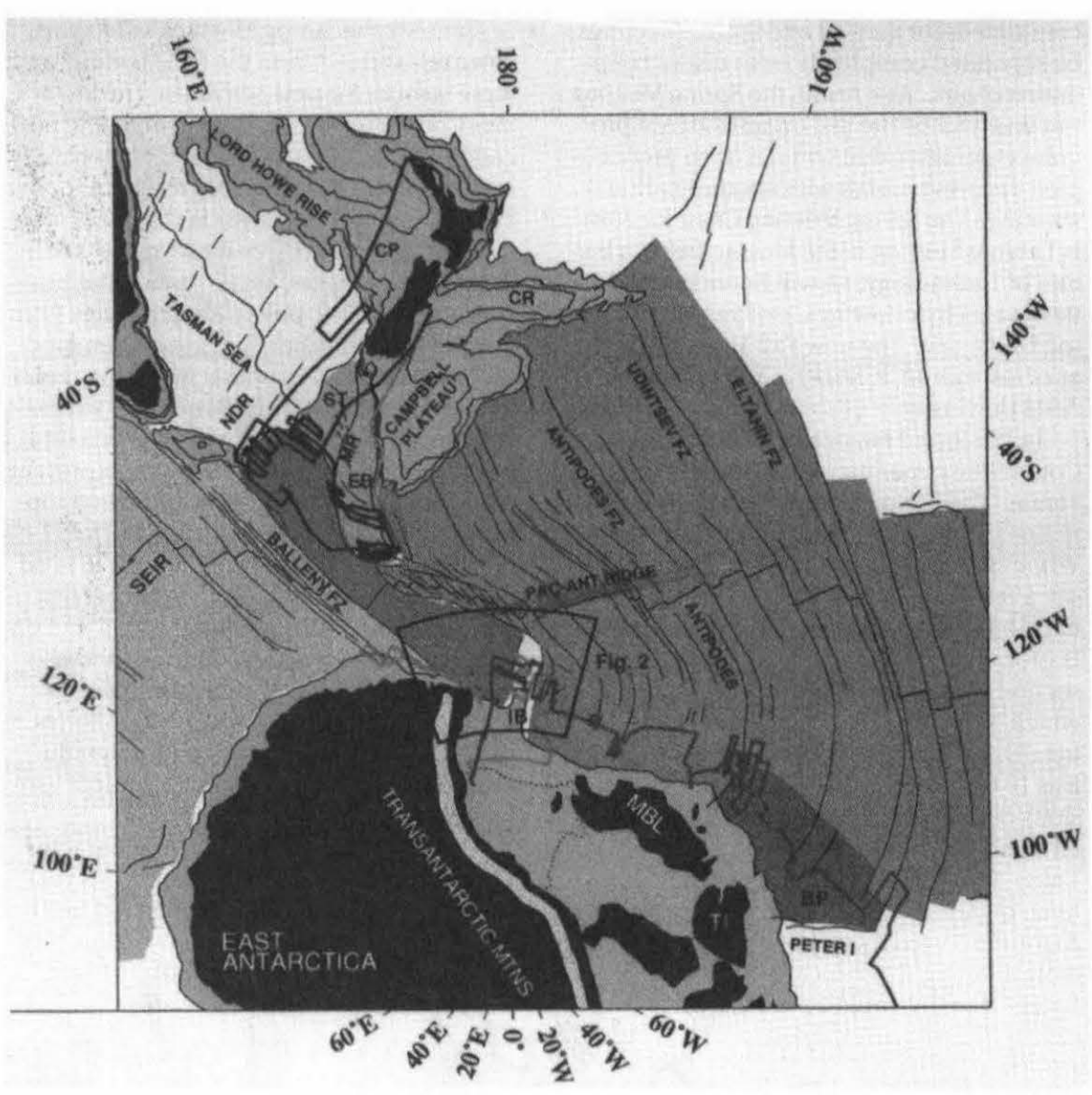

Fig. 1. Track of R/VEwing 95-13 (blue), R/VIB Palmer 96-02 (green) and R/VIB Palmer 97-02 (red). Areas surveyed included the Southeast Indian Ridge (SEIR) spreading corridor east of the Balleny fracture zone (dark green), two basins formed by Pacific-Australia spreading (pink), and the Bellingshausen plate (BP) (dark blue). Oceanic crust generated at the Pacific-Antarctic ridge is shown in light blue, at the SEIR in light green, and at the fossil Tasman Sea spreading center in yellow. The limits of the Ross Ice Shelf are shown by dotted lines. $C P=C h a l l e n g e r P l a t e a u, C R=$ Chatham Rise, $E B=$ Emerald Basin, $I B=I$ selin Bank, $M B L=$ Marie Byrd Land, $M R=$ Macquarie Ridge, $N D R=$ Nella Dan Rift, $S T=$ Southeast Tasman Oceanic Crust, and TI = Thurston Island . Original color image appears at the back of this volume.

Antipodes fracture zone. The portion of the Antarctic plate east of this boundary is referred to as the Bellingshausen plate (dark blue area in Figure 1).

The basic strategy of this project was to use the National Science Foundation icebreaker Nathaniel B. Palmer to survey icecovered areas near Antarctica and the R/V Ewing to survey ice-free areas in the south Tasman Sea. The Ewing was equipped with a swathmapping system and a single-channel seismic streamer; the Palmer, which was also equipped with a swathmapping system, had a 1,200-m multichannel seismic streamer.

The south Tasman Sea was the focus of the Ewing 95-13 cruise. We surveyed the region of early Tertiary spreading on the northwestern end of the Balleny spreading corridor.
A main objective in this region was to determine when spreading started in the corridor and the earliest spreading rates. We found that the boundary between the crust formed at the Tasman Sea spreading center (yellow) and at the SEIR (dark green) corresponds to a region of prominent bathymetric structures, which we refer to as the Nella Dan Rift. The magnetics data show that SEIR spreading along this boundary began around chron 27 (61 Ma) and proceeded very slowly (half rate of about $7 \mathrm{~mm} / \mathrm{yr}$ ) until chron 20 (43 Ma).

The main objective of the surveyed lines in the Emerald Basin and in the region of Southeast Tasman Oceanic Crust was to gather sufficient magnetic anomaly and fracture zone constraints to accurately reconstruct motions between the Australia and
Pacific plates. We found a fairly good record of anomalies starting with anomaly 20 and continuing to about anomaly 10 . Together with analyses of Geosat data [e.g., Sutherland, 1995], these new data will better constrain this critical link of the plate circuit.

The northern Ross Sea, in particular the Antarctic side of the Balleny corridor, was the primary focus of Palmer 97-02. Satellite-derived gravity imagery [Haxby, 1987; Sandwell and Smith, 1997; McAdoo and Laxon, 1997] had revealed several enigmatic tectonic structures in this region (Figure 2) and was a primary guide to our investigations, which included a survey of Scott Rift, the conjugate feature to Nella Dan Rift, marking the southeastern boundary of this corridor. Although not as prominent a topographic feature as on the Tasman Sea side, a buried ridge was imaged in the seismic data.

We also gathered data across a rift structure, which we refer to as the Iselin Trough, that extends northeast of Iselin Bank. This feature has only previously been known from satellite gravity imagery [MCAdoo and Laxon, 1997]. We found that this rift cuts obliquely across crust of normal appearance generated at the Pacific-Antarctic Ridge, and seems to have been formed by intraplate stresses. Between the Scott Rift and Iselin Trough we also surveyed ocean crust (red outline in Figure 2) that appears to have been formed at the Tasman Sea spreading center and which was stranded on the Antarctic plate at the time SEIR spreading initiated along the Nella Dan and Scott Rifts.

Perhaps the most enigmatic feature that we surveyed was the Adare Trough, a prominent graben about $100 \mathrm{~km}$ northeast of Cape Adare. We found a sequence of short wavelength, linear magnetic anomalies roughly paralleling the Adare Trough and extending east to the Hallett Ridge. The strike of these magnetic anomalies is very oblique to the surrounding seafloor fabric and is probably related to rifting in the western Ross Sea. However, the identity and, consequently, the age of these anomalies is not obvious. In fact, there may well have been more than one episode of extension. Toward the north, the Adare Trough merges into SEIR tectonic fabric in the region around anomalies 10 and 12 , roughly 27 - to 30 -million-year-old crust, suggesting that one episode of extension was of this age.

On Palmer cruise 96-02 we extensively surveyed the southernmost section of the Antipodes FZ (Figure 1), the most likely location of the late Cretaceous-early Tertiary plate boundary between the Marie Byrd Land and Bellingshausen sectors of West Antarctica. The magnetic data we collected on the Palmer confirmed that there had been a plate boundary near this fracture zone prior to 


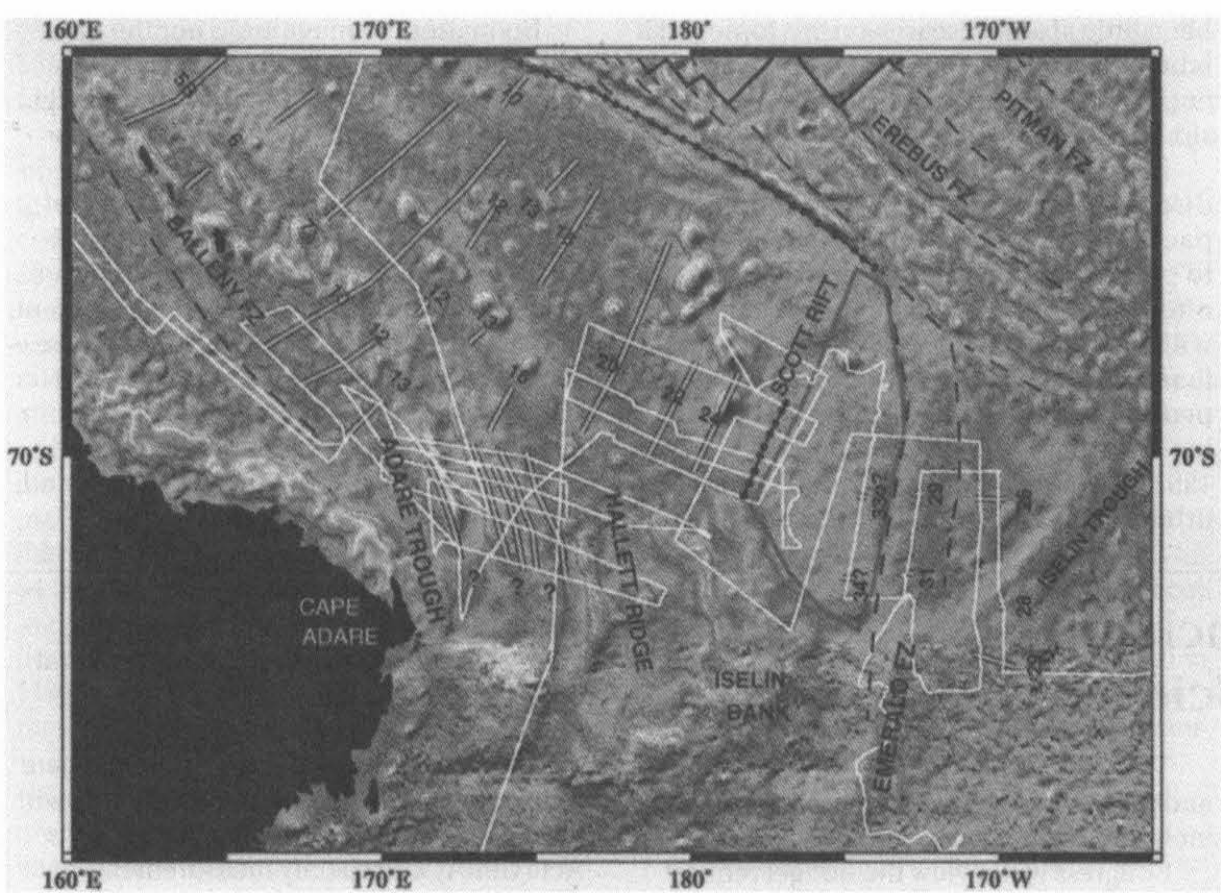

Fig. 2. Tectonic features north of the Ross Sea shown superimposed on the satellite gravity field [Sandwell and Smith, 1997, north of $72^{\circ} \mathrm{S}$; McAdoo and Laxon, 1997, south of $72^{\circ} \mathrm{S}$ ]. A set of magnetic lineations of unknown age between the Adare Trough and Hallett Ridge was probably generated during an episode of rifting in the western Ross Sea. The area outlined in red north of the Iselin Bank is a piece of oceanic crust formed in the Tasman Sea that became attached to the Antarctic plate at the time SEIR spreading initiated east of the Balleny FZ. Heavy dotted lines mark the northern and eastern limits of SEIR spreading. The white line shows the track of R/VIB Palmer 96-02 and 97-02. Original color image appears at the back of this volume.

anomaly 27 time. We found a pattern of westward-converging magnetic anomalies east of the fracture zone, which, when combined with the existing magnetic data on the conjugate part of the Pacific plate southeast of the Campbell Plateau, documented about 200 $\mathrm{km}$ of extension in a NNE-SSW direction. This extension could have been accommodated either by motion between Marie Byrd Land and Thurston Island, or by a totally oceanic Bellingshausen plate that may have existed during the earliest stages of rifting between the Campbell Plateau and Marie Byrd Land [Stock et al., 1996].

These cruises have provided us with a wealth of information about the tectonic evolution of the Pacific-Antarctic-Australia plate circuit and about the origin of several enigmatic pieces of seafloor that hold the key to understanding early plate reorganizations here. Combined with the new insights available through satellite gravity imagery, they should lead to major advances in our knowledge of southwest Pacific plate motions.

\section{Acknowledgments}

We thank the officers, crew, and scientific staff of the R/V Ewing and R/VIB Palmer for their dedicated efforts. This work was funded by NSF grants OPP93-17872 and OCE94-16989 to Scripps Institution of Oceanography and grants OPP93-17318 and OCE94-16779 to Caltech.

\section{References}

Haxby, W. F., Gravity Field of the World's Oceans, National Geophysical Data Center, NOAA, Boulder, CO, 1987.

Lawver, L. A., and L. M. Gahagan, Constraints on timing of extension in the Ross Sea region, Terra Antarctica, 1, 545-552, 1994.

McAdoo, D., and S. Laxon, Antarctic Tectonics: Constraints from an ERS-1 Satellite Marine Gravity Field, Science, 276, 556-560, 1997.

Molnar, P., T. Atwater, J. Mammerickx, and S. M. Smith, Magnetic anomalies, bathymetry and the tectonic evolution of the South Pacific since the late Cretaceous, Geophys, J. R. Astron. Soc., 40, 383-420, 1975.

Sandwell, D. T., and W. H. F. Smith, Marine gravity anomaly from Geosat and ERS-1 satellite altimetry, J. Geophys. Res., 102. 10,039-10,054, 1997

Stock, J., and P. Molnar, Uncertainties in the relative positions of the Australia, Antarctica, Lord Howe, and Pacific plates since the late Cretaceous, J. Geophys. Res., 87 $4,697-4,714,1982$.

Stock, J., and P. Molnar, Revised history of early Tertiary plate motion in the Southwest Pacific, Nature, 325, 495-499, 1987.

Stock, J., S. C. Cande, and C. A. Raymond, Update history of the Bellingshausen Plate (abstract), Eos, Trans. AGU, 77, F647, 1996.

Sutherland, R., The Australia-Pacific boundary and Cenozoic plate motions in the SW Pacific: Some constraints from Geosat data, Tectonics, 14, 819-831, 1995

Wood, R., G. Lamarche, R. Herzer, J. Delteil, and B. Davy, Paleogene seafloor spreading in the southeast Tasman Sea, Tectonics, 15, 966-975, 1996.

\section{Climate Change and Biodiversity Seminar Highlights Knowns and Unknowns}

\section{PAGE 84}

Greenhouse gas emissions can be expected to warm the globe by about $2^{\circ} \mathrm{C}$ over the next 50-100 years. This could have such consequences as raising sea level by $44 \mathrm{~cm}$, thereby affecting 70 million people and destroying the habitats of hundreds of species, increasing the occurrences of such diseases as malaria, and changing the economies of most of the world. All of the physical, chemical, biological, and economic forces at play here are highly nonlinear, leading to feedbacks that could alter all of the findings. These were some of the conclusions of a seminar on "Climate Change and Biodiversity," which attracted over 130 scientists, engineers, and policy makers, mostly from the United Kingdom.

Two of the speakers showed impressive agreement between models and observations of average temperature, suggesting an approximately $2^{\circ} \mathrm{C}$ global warming as a result of an increased level of $\mathrm{CO}_{2}$ in the atmosphere. This is a reduction of about $1{ }^{\circ} \mathrm{C}$ from earlier estimates, because of the inclusion of direct sulfate effects in the model simulations. Described was the need for further research on aerosols, clouds (including the indirect effects of sulfate aerosol), and flux from vegetation. Such work will help project regional distribu- tions of climate change. The nonlinearities inherent in these models demand improved understanding for more reliable "projections." The quotes are to highlight the word chosen by the presenter in preference to "predictions."

In the first of a series of talks on the biological and economic consequence of global warming, the audience was reminded that climate change is but one of five factors of "global" change. The others are population increase, land degradation, ocean pollution, and biodiversity decline. Several, but not all, of these factors turned Easter Island from a paradise to a disaster after human occupation. The analogy to the Earth as a whole did not have to be made for the audience to realize the parallels.

Nonlinearity, discussed so much in the physical papers, applies even more in biol- 